\title{
Imagining, Recognizing and Discriminating: Reconsidering the Ability Hypothesis ${ }^{1}$
}

BENCE NANAY

Syracuse University

\begin{abstract}
According to the Ability Hypothesis, knowing what it is like to have experience E is just having the ability to imagine or recognize or remember having experience E. I examine various versions of the Ability Hypothesis and point out that they all face serious objections. Then I propose a new version that is not vulnerable to these objections: knowing what it is like to experience $\mathrm{E}$ is having the ability to discriminate imagining or having experience $\mathrm{E}$ from imagining or having any other experience. I argue that if we replace the ability to imagine or recognize with the ability to discriminate, the Ability Hypothesis can be salvaged.
\end{abstract}

\section{Introduction}

One big question in the philosophy of mind is the following: what is it like to have an experience of a certain kind. A further, no less significant, question is what it means to know what it is like to have an experience of a certain kind. This question is important for at least two reasons.

The first reason is that it would be impossible to imagine or remember having an experience without knowing what it is like to have that experience. I cannot imagine the taste of a Sonoma Valley Pinot Noir if I do not know what Sonoma Valley Pinot Noir tastes like (cf. McGinn 2000). Similarly, I cannot remember the taste of a Sonoma Valley Pinot Noir if I do not know what Sonoma Valley Pinot Noir tastes like (although I may still remember that I once tasted Sonoma Valley Pinot Noir). Thus, much of our mental life is dependent on such knowledge.

I am grateful to Hugh Mellor, Robert Van Gulick and André Gallois for detailed comments on earlier versions of this paper. I am also grateful to the participants of my seminar on imagination at Syracuse University. 
The second reason why we should be interested in the analysis of 'knowing what it is like to have an experience' is that this issue came to the forefront of philosophical discussions of consciousness as an important feature of the Knowledge Argument.

According to the Knowledge Argument, Mary is one of the world's leading vision scientists, an expert on color vision. As a matter of fact, she knows all physical facts that can be known about color. However, she has never experienced colors: she has spent her entire life in a black and white room. When she leaves the room and looks at a red rose, she learns something: she did not know what it is like to experience red, but after having looked at the red rose, she does know what it is like to experience red. But, ex hypothesi, she knew every physical fact that is to be known about color. What could she learn then upon looking at the rose? The Knowledge Argument is supposed to show that our first-personal experiences cannot be captured by physical facts. There must be something irreducibly non-physical about experience.

One way to argue against this conclusion is to claim that what Mary acquired when she looked at the rose was not propositional knowledge, but an ability: an ability to imagine or recall or recognize certain experiences. This is the Ability Hypothesis. As David Lewis put it, "knowing what an experience is like [...] isn't knowing-that. It's knowing-how" (Lewis 1990, p. 516). Thus, the suggestion is that to know what it is like to have an experience of a certain kind is to have certain abilities. Mary acquired certain abilities. She did not have these abilities in her black and white room, she has them now. There is nothing about her story that should convince us that first-personal experiences cannot be captured by physical facts.

Although the Ability Hypothesis has become a fashionable topic in the philosophy of mind because it could be used to counter the Knowledge Argument, my primary aim will be to understand what it is to know what it is like to have an experience. The applicability of this notion on the Knowledge Argument case is a secondary, albeit important question.

I will examine various versions of the Ability Hypothesis and point out that they all face serious problems. Finally, I argue for a new version of the Ability Hypothesis that is not vulnerable to these objections. Before I do so, however, two points of clarification need to be made.

First, nothing I say here will assume that 'knowledge how' is a different kind of knowledge from 'knowledge that'. Gilbert Ryle famously argued for such a distinction (Ryle 1949) and most versions of the Ability Hypothesis take it for granted that 'knowledge how' is irreducible to 'knowledge that'. That is why Mary can acquire the knowledge of what it is like to experience red, which is supposed to be an instance of 'knowledge how', in spite of the fact that she already possesses every possible instances 
of 'knowledge that' about colors. Recently, however, it has been argued that 'knowledge how' is just a special case of 'knowledge that' (Stanley \& Williamson 2001). If this is true, then one of the main premises of the Ability Hypothesis is questioned (see Alter 2001, see also the concluding section of the Stanley \& Williamson 2001 article). Because of these worries, in order to preserve the generality of the Ability Hypothesis, I will not take it for granted that 'knowledge how' is different from 'knowledge that'. I will not use the term 'knowledge how' at all: I use the concept of 'ability' instead: to know what it is like to experience red is to have certain abilities. I do not take this way of phrasing the Ability Hypothesis interestingly different from the one that uses 'knowledge how', but in order to avoid the possible objection along the lines of Stanley \& Williamson 2001, I will use this way of stating the Ability Hypothesis. ${ }^{2}$

Second, the Ability Hypothesis was intended as a physicalist defense against the anti-physicalist Knowledge Argument (Lewis 1983, 1990), but I would like to remain neutral about these implications of the debate. Some of the proponents of the Ability Hypothesis are anti-physicalist (Mellor 1992/1993) and a number of those who argued against the Ability Hypothesis are physicalist. The question about what Mary learned (and the question about when we can say that I know what Pinot Noir tastes like) is an important one even if we leave physicalism aside.

\section{Ability Hypotheses}

The Ability Hypothesis is usually treated as a monolithic category. It is important to note, however, that different versions of it vary considerably. ${ }^{3}$ We can differentiate three significantly different versions:

(AH1) Knowing what it is like to experience $\mathrm{E}$ is having the ability to imagine having experience $\mathrm{E}$.

This strategy may not be as unproblematic as it seems. Both Alter's piece (Alter 2001, section 4, option 1) and the Stanley \& Williamson article (Stanley \& Williamson 2001, section IV) express doubts that this move would help the advocates of the Ability Hypothesis. Stanley and Williamson argue that the ability to imagine is or at least implies an exercise of knowledge-how. Alter argues that replacing knowing how with abilities does not address the main objection raised against the Ability Hypothesis. For the sake of simplicity, I put these issues about knowledge-how on the side.

3 Diana Raffman makes an important distinction between two possible explananda: knowing what it's like to see red and knowing how red things look (Raffman 2005, see also Graham \& Horgan 2005, who are also endorsing this distinction). She argues that "[h]ow red things look is learned by perceiving [whereas] what it's like to see (look at) red is learned by introspecting" (Raffman 2005, p. 198). I agree with Raffman that the important question is the former and everything I say in this paper can be rephrased using that terminology. For simplicity, I will keep using the more widespread characterization 'knowing what it's like to see red'. 
This was Laurence Nemirow's original proposal (Nemirow 1980, p. 475), which kicked off the debate. In a more elaborated version of his argument, he writes:

Knowing what an experience is like is the same as knowing how to imagine having the experience (Nemirow 1990, p. 495).

The problem with this proposal is that if I have wild enough imagination, I can imagine having pretty much any experience, including that of being a bat. Of course, I may be completely wrong and imagine experiences incorrectly. But the ability to imagine having experience $\mathrm{E}$ incorrectly is unlikely to constitute the knowledge of what it is like to have experience E. Knowing what experience $\mathrm{E}$ is like, if it is to be analyzed as having the ability to imagine, seems to imply the ability to imagine having experience E correctly. Thus, the ability to imagine having experience $\mathrm{E}$ is not sufficient for accounting for knowing what experience $\mathrm{E}$ is like. We need something more.

The most famous and most frequently analyzed version of the Ability Hypothesis brings in recognitional (and perhaps other) abilities besides imaginative ones. This is the proposal put forward by David Lewis:

[K]nowing what it is like is the possession of abilities: abilities to recognize, abilities to imagine, abilities to predict one's behavior by imaginative experiments (Lewis 1983, p. 131).

And also:

The Ability Hypothesis says that knowing what an experience is like just $i s$ the possession of these abilities to remember, imagine, and recognize (Lewis 1990, p. 516).

To sum up:

(AH2) Knowing what it is like to experience $\mathrm{E}$ is having the ability to imagine having experience $\mathrm{E}$ as well as having the ability to recognize having experience $\mathrm{E}$ (and perhaps even remember having experience E). ${ }^{4}$

$4 \quad$ When analyzing Lewis' version of the Ability Hypothesis, I will put aside the discussion surrounding the ability to remember (see Mellor 1992/1993) and focus on the abilities mentioned here: the ability to imagine and to recognize. All the arguments I give for or against this version in this paper apply (if they do) regardless of whether we omit the reference to the ability to remember. 
The third version of the Ability Hypothesis can be seen as a compromise between (AH1) and (AH2). The suggestion could be thought of as a version of (AH1) as it says that knowing what it is like to experience $\mathrm{E}$ is having the ability to imagine having experience $\mathrm{E}$ correctly. But what it means to imagine experiences correctly brings in recognitional abilities. It could also be thought of as a version of (AH2), because it gives a specific proposal for the way in which our imaginative and recognitional abilities must combine in order for us to know what an experience is like. D. H. Mellor writes:

To know what experiences of a certain kind are like I must, when I imagine them, imagine them correctly, i.e. in a way that makes me recognize them when I have them (Mellor 1992/1993, pp. 4-5).

In other words:

(AH3) Knowing what it is like to experience $\mathrm{E}$ is having the ability to imagine having experience E correctly, that is, in such a way that would enable one to recognize having experience $\mathrm{E}$.

Before we turn to the objections to these various versions of the Ability Hypothesis, we need to make yet another distinction between different interpretations of the Ability Hypothesis. The distinctions I made above were between versions of the explanans: the question was what abilities constitute the knowledge of what it is like to experience red. Now, we need to differentiate between two different possible versions of the explanandum:

(a) Knowing what it is like to have a specific token experience e*.

(b) Knowing what it is like to have experiences of type E.

Interestingly, most formulations of the Ability Hypothesis (including all but one of the quotes I gave in this section) do not make the difference between (a) and (b) explicit. I assume that the philosophically interesting question is about the nature of (b) and this paper is supposed to be an explication of (b). But it is important to distinguish (b) from (a), which often come up in counterarguments to claims about (b).

(a) is not a very interesting kind of knowledge. If I know what it is like to have a specific token experience $e^{*}$, then it is likely that I am either having this experience right now, or I have experienced it and I have a truly excellent episodic memory. But whatever the correct analysis of this kind of knowledge is, what is important for our purposes is that (a) has little to do with the Knowledge Argument. What Mary was 
supposed to learn when she first looked at the red rose was not what it is like to experience a specific token experience. She learned what it is like to experience red. I have very little to say about (a) in this paper.

Some of the criticisms of the Ability Hypothesis apply in the case of all three proposals, some others only apply to some of them. I will not rehearse the various objections to the necessity and the sufficiency claim of the three versions of the Ability Hypothesis (see Joyce 2003, Loar 1997, Conee 1994, Gertler 1999 among others. See also the recent exchange between Alter 2006 and Jackson 2006. Lycan 1996, chapter 5 and Tye 2004 gave a very good summary of these possible objections and Tye 2004 (section II) as well as Nemirow 2006 give a good overview of why some of the most frequently cited arguments against the Ability Hypothesis fail).

Instead, I will focus on one specific objection that applies in the case of all these three versions and argue that it is not a good argument against the Ability Hypothesis in general. A new, fourth version of the Ability Hypothesis can handle this objection and give us a way of salvaging the Ability Hypothesis.

There is a quite simple reason why we would need to be suspicious about (AH2) and (AH3). Both (AH2) and (AH3) make references to our recognitional abilities. But some people who became blind late in their life still claim to know what it is like to experience red and we have no reason to doubt that they do so. They (at least some of them, see Aleman et al. 2001, Hollins 1985, Sachs 2003) are capable of visualizing red, but they are most certainly incapable of recognizing red, given that they are blind. They know what it is like to experience red, but they lack the ability to recognize red. Therefore, (AH2) is wrong. They also lack the ability to imagine red in such a way that this would help them to recognize red. Therefore, (AH3) is also wrong. ${ }^{5}$

Thus, (AH2) and (AH3) need to be discarded: we are back with (AH1). But we have seen that (AH1) in itself will not do, because it does not disqualify the ability to imagine having an experience incor-

The defenders of (AH2) and (AH3) could argue that although blind people lack the ability to experience red, they do have the ability to recognize red if they were to experience it-it's just that they cannot experience it. The main point is that the ability to recognize is a conditional ability: an agent has the ability to recognize red if it is true that were she having the experience of red, she would recognize it. Note, however, that if we allow for such conditional abilities, then the concept of ability we end up with will not only be very different from our everyday conception (the ability to travel with the speed of light, of example, would count as an ability we all have), but it will not be applicable to the original Knowledge Argument case either. It was true of Mary back in the black and white room that if she had the recognitional and imaginative skills she has now (after her escape), she would be able to imagine and recognize red. Still, if we described her as already having the ability to imagine and recognize red back in the black and white room, then it is unclear what she learnt when she looked at the rose. 
rectly from the imaginative abilities Mary is supposed to acquire. None of the three versions of the Ability Hypothesis can respond to the objection just raised.

\section{The Ability to Discriminate}

We have seen that if we want to identify knowing what it is like to experience $\mathrm{E}$ with having the ability to imagine, we have to specify what it means to imagine an experience correctly. This is exactly what (AH3) attempts to do, but as it does so with the help of the notion of recognitional abilities, it is vulnerable to the objection I raised here. If, however, we find a way to specify what it means to imagine an experience correctly without bringing in recognitional abilities, we could avoid the same objection. This is precisely what I aim to do in this section.

Instead of bringing in recognitional abilities, I will use a kind of ability that has not yet been suggested in the Ability Hypothesis literature: the ability to discriminate. ${ }^{6}$ My proposal is very simple:

(AH4) Knowing what it is like to experience $\mathrm{E}$ is having the ability to distinguish imagining or having experience $\mathrm{E}$ from imagining or having any other experience.

(AH4) is a disjunctive definition: the ability to distinguish imagined experiences (from all other experiences) and the ability to distinguish real experiences (from all other experiences) are both sufficient for knowing what it is like to experience $\mathrm{E}$.

The imagined experience disjunct of (AH4) could be thought of as similar to (AH3) in as much as it also cashes out what it is like to experience $\mathrm{E}$ in terms of the ability to imagine having experience $\mathrm{E}$ correctly. Having the ability to imagine having experience E correctly, that is, in such a way that would enable one to distinguish imagining experience $\mathrm{E}$ from imagining or having any other experience entails knowing what it is like to experience E. It is different from (AH3), however, in that it uses the ability to differentiate imagining experience $\mathrm{E}$ from imagining or having other experiences (and not the ability to recognize) for specifying the ability to imagine correctly.

It is important to emphasize that the ability to distinguish imagined experiences is a sufficient but not a necessary condition for knowing what it is like to experience E. After all, there may be some cases where

Diana Raffman talks about 'discriminatory' capacities (Raffman 2005), but she seems to equate these abilities to recognitional ones (see esp. p. 198 and p. 199), which, as I argued above, are problematic. I will attempt to make a case for the ability to differentiate without bringing in recognitional abilities at all. 
an agent does not have the ability to distinguish imagining experiences, but as she has the ability to distinguish her real experience $\mathrm{E}$ from her other real experiences, she may be described as knowing what it is like to experience $\mathrm{E}$.

Earl Conee (Conee 1994, p. 138, see also Alter 1998) argued that if a person lacks the ability to imagine any color experiences, she would still know what it is like to have an experience of red while looking at an object that appears red to her.

There may be some empirical problems with this objection: it is far from clear that such cases exist and that they could even exist. ${ }^{7}$ Perhaps perceiving colors presupposes the ability to visualize colors. Peter Strawson, for example, argued that a necessary feature of perception is in fact imagination (Strawson 1974, see also Nanay forthcoming). Further, it has been pointed out that the most frequently quoted empirical cases where agents were capable of perceiving but not visualizing are not conclusive (Marotta \& Behrmann 2004). It is, of course, possible that an agent can perceive and she also has visual imagery, but she cannot exercise her visual imagery at will. This example, however, would not constitute a counterexample to the imagined experience disjunct of (AH4), as she could still differentiate (non-voluntarily) imagining of $\mathrm{E}$ from other (also non-voluntary) imaginings.

Because of these considerations, I am not convinced that there are indeed such agents. But even if there are, this does not pose any problem for (AH4), since having the ability to distinguish imagined experiences is not necessary for knowing what it is like to have a certain kind of experience. My claim was that knowing what it is like to experience $\mathrm{E}$ is having the ability to distinguish imagining or having experience $\mathrm{E}$ from imagining or having any other experience. And the person lacking the ability to imagine (therefore, to distinguish imagining) experiences can still have the ability to distinguish having experience $\mathrm{E}$ from having any other experience. We have no reason to deny that a person who does not have the ability to imagine color experiences would also lack the ability to distinguish two color experiences: just because she cannot imagine, she could still differentiate two color samples she is staring at. Thus, according to our definition, she could still be described as knowing what it is like to experience E.

I am not concerned with metaphysical possibility here: I assume throughout the paper that the Ability Hypothesis is a claim about actual human agents and their knowledge of what it is like to have certain experiences and not about some metaphysically possible perceivers and their knowledge. Thus, it would jeopardize Conee's objection if it turned out to be the case that no human agent can perceive without being able to imagine. The metaphysical possibility of such cases (where a perceiver can perceive without being able to imagine) is irrelevant. 
Conversely, we also need the reference to imagined experiences in the definition, otherwise (AH4) would be vulnerable to the objection I raised in the last section. Blind people, if they are capable of visualizing, can indeed have the ability to differentiate their imagining red from their imagining blue. And in this case we would indeed be justified to say that they know what it is like to experience red.

Thus, we need both disjuncts in (AH4): both the reference to distinguishing imagining experiences and to distinguishing having experiences. ${ }^{8}$

Finally, I need to warn against a possible misunderstanding of the definition of (AH4). One may argue that there is a very obvious counterexample to this definition. Suppose that I am an excellent tastedistinguisher. I don't know much about wine, but my taste-buds are so sensitive that I can differentiate any two tastes. Suppose that I taste a Sonoma Valley Pinot Noir for the first time in my life. I can easily distinguish it from any other taste as I am such an excellent taste-distinguisher. Thus, we have a contradiction. On the one hand, when presented for the first time with a glass of Sonoma Valley Pinot Noir, I have the ability to distinguish this taste from any other taste. On the other hand, intuitively we are inclined to say that I do not know what Sonoma Valley Pinot Noir tastes like.

This objection to (AH4) is important because it draws attention to a possible type-token ambiguity in the definition. We have seen that the explanandum of the Ability Hypothesis is about an experience type: what we want to understand is what it takes to know what it is like to have an experience of a certain kind. Thus, ideally, the explanans also needs to be about an experience type and in (AH4) the explanans is indeed about experience types - see section VII for further analysis of the typing of experiences in the explanandum and the explanans.

Having an experience is always having a token experience, therefore, distinguishing having experience $\mathrm{E}$ from any other experiences is distinguishing one token experience from another. But 'the ability to differentiate having experience $\mathrm{E}$ and any other experience' in my definition

It may be worth noting that the ability to differentiate (imagined or actual) experiences is also important if we want to make sense of the concept of a 'quality space' (Clark 1993, 2000). "A quality space is an ordering of the qualities presented by a sensory modality in which relative similarities among those qualities are represented by their relative distances" (Clark 2000, p. 1). Two points in one's quality space are distinct if one can distinguish between them. As Austen Clark writes, "[r]elations of matching and discriminability are [...] used to order the qualities that [the] stimuli present" (Clark 2000, p. 4, see also p. 6). Thus, one's ability to differentiate is what makes one's quality space the way it is. I need to emphasize though that nothing I say in this paper relies on Clark's account of quality space. 
is an ability involving experience types. Thus, the question is how we get from tokens to types (see Section VII for more details). The short answer is that 'the ability to differentiate having experience $\mathrm{E}$ and any other experience' in my definition is supposed to be read as having the ability to distinguish having any token experience of type E from any token experience that is not of type $\mathrm{E}$.

Thus, the excellent distinguisher of tastes may have the ability to distinguish the token experience she has from every other experiences (or even the extremely narrow experience type she has a token of), but she does not have the ability to differentiate tokens of the experience type of Sonoma Valley Pinot Noirs from every other experiences. Thus, according to (AH4), she does not know what Sonoma Valley Pinot Noir tastes like.

\section{Mislabeling}

There is an obvious consequence of (AH4) that one could take to be a problematic feature of the view. Suppose that I can differentiate between the (imagined or actual) taste of Sonoma Valley Pinot Noirs and any other (imagined or actual) taste, including the taste of Central Coast Californian Pinot Noirs. According to (AH4), this implies that I know what Sonoma Valley Pinot Noir tastes like. But suppose that although I am excellent at distinguishing wines, I have never seen or heard the words Sonoma Valley Pinot Noir: all the numerous bottles of Sonoma Valley Pinot Noir I have drunk have had their labels missing. I call the experience of Sonoma Valley Pinot Noir something else, let's just say, I call it X. Could we claim that I know what Sonoma Valley Pinot Noir tastes like? I don't even know what the expression 'Sonoma Valley Pinot Noir' is supposed to stand for, after all.

I think we should indeed claim that I know what Sonoma Valley Pinot Noir, which I incidentally call X, tastes like. The problem is not with my knowledge of wine, but with my labeling: I mislabeled Sonoma Valley Pinot Noir. If I am told that what I have been calling X is in fact referred to by other people as Sonoma Valley Pinot Noir, this would not change anything about my knowing what certain type of wine (that is usually referred to as Sonoma Valley Pinot Noir) tastes like. It would rather change my way of referring to this type.

To take one of Lewis's examples, I may be very good at distinguishing the imagined experience of vegemite and marmite. I can also differentiate imagining either of these from any other taste. But I have never tasted either vegemite or marmite. When I finally do taste them, I realize that although what I imagined to be the taste of vegemite is in fact the taste of marmite and vice versa. Was I wrong before? In a 
way, I was. I did know what it was like to taste vegemite, but I labeled it to be marmite. Again, my ability to differentiate imagined experiences was perfect. I just labeled the imagined experiences I was so good at differentiating incorrectly. ${ }^{9}$

\section{Possible Problems with the Necessity Claim}

One could argue that the abilities mentioned in (AH4) are not necessary for knowing what it is like to have experience E. The suggestion is that (AH4) is too strong: someone can be described as knowing what it is like to experience $\mathrm{E}$, but she does not have the ability to distinguish imagining or having $\mathrm{E}$ from imagining or having any other experiences.

Michael Tye has the following objection to the Ability Hypothesis (Tye 2004, section III). Suppose that Mary is looking at a rose. She is having an experience of the color of the rose, which is a certain specific shade of red, say, red17. She lacks the ability to imagine or recognize the same exact shade, because she cannot tell red17 apart from red19 or red15. Still, as she is gazing at the rose, she certainly knows what it is like to experience this specific shade of red. So it is possible to know what it is like to experience red 17 without having the ability to imagine or recognize having the experience red17. Thus, having the ability to recognize having experience $\mathrm{E}$ is not a necessary condition for knowing what experience $\mathrm{E}$ is like.

Regardless of whether this is a good objection against (AH1), (AH2) or (AH3), it needs to be examined whether a version of this objection could pose a problem for (AH4). If Tye is right, then Mary knows what it is like to experience red17, but perhaps she does not have the ability to distinguish the (imagined or actual) experience of red17 from any other (imagined or actual) experience, say, that of red15. How could we defend (AH4) against this objection?

When Mary is looking at the rose, she certainly has the ability to differentiate imagining and even having this experience (of the specific shade of the rose she is looking at) from imagining or having any other experience. If we put a color sample of red15 next to the red17 rose,

Thus, we may be able to distinguish (actual or imagined) experiences of red but still mislabel these experiences. A case could be made that the ability to distinguish some (actual or imagined) experiences (supposedly experiences of red) is, however, a necessary condition for correctly labeling something as red or using the term 'red' correctly. Austen Clark makes a very similar point: "one needs a shared sense of qualitative similarity - those capacities of discrimination, matching, and relative similarity that order the qualities in a given sensory modality - and presentation of a sufficient number of paradigms and foils (samples within and without the extension of the term) so that one learns the correct use of the term" (Clark 2000, p. 28, see also Clark 1993). 
she can certainly distinguish these two experiences (see also Nemirow 2006). Thus, at the moment when she is looking at the rose and knows what it is like to experience the exact shade of color this rose has, she also has the ability that is supposed to define knowing what it is like to experience this shade of red: the ability to distinguish imagining or having this experience from imagining or having any other experiences.

A week later, Mary no longer has this ability: she can no longer tell imagining or having the specific shade of red17 from the very similar shades of red15 or red19. But this is exactly what we should expect, because at this point (a week after having looked at the rose) she does not know what it is like to experience red17 either.

\section{Possible Problems with the Sufficiency Claim}

One could also argue that the abilities mentioned in (AH4) are not sufficient for knowing what it is like to have experience E. A more specific worry was raised against $(\mathrm{AH} 1)$ and $(\mathrm{AH} 2)$ by Conee (Conee 1994, pp. 138-139, see also Raymont 1999).

Conee gives the following example. Martha is "highly skilled at visualizing an intermediate shade that she has not experienced between pairs of shades that she has experienced" (Conee 1994, p. 138). Martha is not familiar with the shade of cherry red. Nevertheless, she has experienced the shade of fire engine red and she has also experienced the shade of burgundy. Once Martha is told that cherry red is the intermediate shade between burgundy and fire engine red, she can imagine having the experience of cherry red. She has the ability to imagine having the experience of cherry red, but she does not know yet what it is like to experience cherry red. She will know it once she in fact visualized it, but right after she was told that cherry red is the shade between burgundy and fire engine red, she does not know this yet. Thus, it is possible to have the ability to imagine cherry red without knowing what it is like to experience cherry red.

This argument may work in the case of (AH1) (although Noordhof 2003, pp. 24-25 argued otherwise), but it does not work in the case of (AH4). When Martha is being told about the shade of cherry red, she may have the ability to imagine this shade (she is "highly skilled at visualizing", after all), but my claim is that she does not have the ability to differentiate imagining or experiencing cherry red from any other color experiences. Even if she has the ability to imagine cherry red, she may not be able to differentiate this imagined experience from the imagined experience of, say, rubine red. She will acquire the ability to differentiate the imagined experience of cherry red from other imagined experiences, after she imagined experiencing cherry red (and maybe 
compared this imagined experience to other ones), but she does not have this ability at the moment. Martha has the ability to acquire the ability to differentiate cherry red from other shades, but she does not have this ability just yet.

It is a tricky question whether something is an ability or an ability to acquire an ability (see Noordhof 2003, pp. 24-25 for a good summary on this). The following analogy may be helpful.

I don't speak Swahili. But if I sign up for a Swahili course, I will acquire the ability to speak Swahili. In this case, there is an activity, that of taking the language course, that comes before the acquisition of the ability. Thus, I can be described as having the ability to acquire the ability to speak Swahili while lacking the ability to speak Swahili.

Paul Raymont argued that in the case of the abilities that are supposed to play a role in the Ability Hypothesis, there is no such time gap between the activity that makes the ability possible and the ability itself (Raymont 1999, see also Noordhof 2003, p. 24). More importantly, when Martha interpolates on the two known experiences of red, by performing this very act, she imagined the unknown shade of cherry red. It would be misleading to describe Martha as first interpolating and then after this interpolation has enabled her to acquire the ability to imagine cherry red, imagining cherry red. She, so Raymont argues, imagined cherry red by interpolating on the two other colors. Thus we have no reason to describe these scenarios as ones where one has the ability to acquire an ability.

Note, however, that while this argument may work in the case of the ability to imagine (the original case Raymont argues against), as Martha does have the ability to imagine cherry red in the very moment when she is told that cherry red is the shade between fire engine red and burgundy, the abilities (AH4) talks about are different in this very respect. Martha does not have the ability to differentiate cherry red from any other experiences at the moment she is told that cherry red is the intermediate shade between fire engine red and burgundy. She will need to do a lot of comparing and contrasting before she can be described as being able to differentiate this so far unknown shade from every other shades - it takes time to acquire this ability. Thus, Martha's case described in the framework of (AH4) is quite similar to the learning Swahili example.

Thus, when Martha was just told that cherry red is the shade between burgundy and fire engine red, she does not have the ability to differentiate imagining or having cherry red experiences from imagining or having any other experiences. And she does not yet know what it is like to experience cherry red. There is no contradiction. 


\section{Yet Another Possible Objection}

There is yet another possible objection against the Ability Hypothesis we would need to consider. I will start with the original versions of the Ability Hypothesis and then turn to (AH4).

The explanadum of the Ability Hypothesis, as we have seen in section II, is about types of experiences. One would expect, then, that experiences in the explanans are typed in the same way as they are in the explanadum. But they are not.

It is a controversial question whether we can imagine an experiencetype. One could argue that sensory imagination has a surprising specificity: we cannot imagine a chair in general, for example. We can only imagine specific chairs, albeit with some details not filled in. ${ }^{10}$ The same goes for imagining experiences. One cannot imagine the experience of wine in general, but only a certain specific wine-experience. I do not want to endorse this line of reasoning and rush to the conclusion that we can only imagine experience tokens. It may be the case that we can imagine very narrowly individuated experience types (see Martin 2001, p. 275, Matthen 2005, pp. 319-320). But the problem is that these experience types we imagine (or we have the ability to imagine) are individuated differently from the way experience types are individuated in the explanadum.

More precisely, the problem is that experience types in the explanans are more narrowly individuated than experience types in the explanandum. Take the following example. I know what wine tastes like. Thus, the experience type in the explanadum is a very broadly individuated experience type: that of wine. But the experience type in the explanans is much more narrowly individuated: one cannot imagine the taste of wine in general: one can imagine the taste of a Merlot or a Chablis (or at least the taste of red wine or white wine), but not the taste of wine per se. But if experiences in the explanans are more narrowly individuated than experiences in the explanandum, then it is unclear how we are supposed to get from abilities to imagine certain narrow experience types to knowing what it is like to have some completely different, much more broadly individuated experience-type.

One option would be to use existential quantification: one knows what it is like to have experience of type $\mathrm{E}$ if and only if there is an experience that is a subcategory of type $\mathrm{E}$, call it $\mathrm{E}^{*}$, such that one has the ability to imagine $E^{*}$. In other words, if and only if one has the ability to imagine a (any) narrower experience type of $\mathrm{E}$.

10 This was already observed by Berkeley ( $A$ Treatise Concerning the Principles of Human Knowledge, Introduction, Paragraph 10) and Hume (A Treatise of Human Nature, Part I, Section VII). 
This will not give us a satisfactory account of knowing what it is like to have experiences of type E. Suppose that I have never tasted wine and I take a sip of Sonoma Valley Pinot Noir (from a specific year, vineyard, bottle). I may be very good at imagining specific tastes so I can imagine this very finely individuated experience type ever after. I may also be able to imagine this experience type in such a way that it would help me recognize it. Thus, I have the relevant abilities, but what did I learn? Did I acquire the knowledge of what it is like to taste wine? Or of what it is like to taste red wine? Pinot Noir? Sonoma Valley Pinot Noir? One problem is that this account will not be able to discriminate between these options. Another problem is that none of these options sound too convincing. As I have never tasted any other wine, in what sense could we say that I know what Pinot Noirs taste like? It does not sound plausible to say that it is possible to know what it is like to taste Pinot Noirs without having any experience or knowledge of the contrast class.

Another option would be to use something like universal quantification: one knows what it is like to have experience of type $\mathrm{E}$ if and only if for every (or most) narrower experience type of $\mathrm{E}, \mathrm{E}^{*}$, one has the ability to imagine them.

The strict universal quantification will not do as no-one, not even the very best sommelier, has the ability to imagine every finely individuated subcategory of the Pinot Noir experience type. But we encounter similar problems even if we loosen this criterion and we only require that for most narrower experience type of $\mathrm{E}$, one has the ability to imagine them. Our mind is just too limited for making it possible that anyone could have the ability to imagine most experiences of such a vast experiencetype (which, of course, includes all the terrible home made Pinot Noirs).

But maybe the truth is somewhere in between. Maybe one knows what it is like to have experience of type $\mathrm{E}$ just in case one has the ability to imagine/recognize sufficiently many subcategories of the experience type E. Not all, not some, but sufficiently many. Here, the problem is the following. If I can imagine sufficiently many experience types of Pinot Noir, but they all happen to be Sonoma Valley Pinot Noirs, then in what sense could we say that I know what Pinot Noirs taste like? I lack the ability to imagine experience types of a Central Coast Pinot Noir, after all and they are also experiences of Pinot Noir. If, on the other hand, these 'sufficiently many' Pinot Noir experience types are somehow evenly distributed across regions (and years as well as vineyards), then perhaps we can indeed say that I do know what Pinot Noirs taste like. If we have the ability to imagine/recognize 'sufficiently many' subcategories of the experience type $\mathrm{E}$, then, depending on how they are distributed, sometimes we do know what it is like to experience E, while some other times, we don't. This way of connecting 
the more narrowly individuated experiences in the explanans are the more broadly individuated experiences in the explanandum does not seem to be a viable option either.

I am not entirely certain that the fact that experiences in the explanans of the Ability Hypothesis are more narrowly individuated than experiences in the explanandum and that there is no clear way of connecting the two would indeed be a knock-down objection against (AH1), (AH2) and (AH3), but what is important for our purposes is that (AH4) is certainly not vulnerable to these worries. This will also help us to clarify a possible type/token ambiguity in my definition.

As we have seen, knowing what an experience is like is knowing what an experience type $\mathrm{E}$ is like. Having an experience, on the other hand, is always having a token experience, therefore, distinguishing having experience $\mathrm{E}$ from any other experiences is distinguishing one token experience from another. Thus, 'having the ability to differentiate having experience $\mathrm{E}$ and any other experience' in my definition is supposed to be read as having the ability to distinguish having any token experience of type $\mathrm{E}$ from any token experience that is not of type $\mathrm{E}$.

Similar considerations apply in the case of the other disjunct of my definition. The experience-types we imagine are more finely individuated than the experience type we know what it is like to experience. Thus, 'having the ability to differentiate imagining experience $\mathrm{E}$ and imagining any other experience' in my definition should be read as having the ability to differentiate imagining any experience of type $\mathrm{E}$ (that is, any experience type that is a subcategory of E) that one can imagine and imagining any experience that is not of type $\mathrm{E}$.

Thus, this version of the Ability Hypothesis is not vulnerable to the possible objection I have been considering here. In general, agent A knows what it is like to have experience of type $\mathrm{E}$ if and only if agent A has the ability to differentiate imagining or having experiences that belong to type $\mathrm{E}$ from experiences that do not belong to type E. Experiences in the explanans and in the explanandum are typed in the very same way.

\section{Conclusion}

Let us go back to Mary. What she learns when she looks at the red rose is what it is like to have the experience of that specific shade of red. She does not learn what it is like to see red per se. She will learn that much later, after having been exposed to more token experiences of red. But she does learn what it is like to have an experience of a much more narrow type: experiences of the shade of red that happens to be the color of the rose. According to (AH4), this means that she 
acquires the ability to differentiate imagining or having this experience from imagining or having any other experiences (i.e., the experience of black or white, the only color-experiences she was familiar with). Thus, the only thing that changed was that she acquired an ability: the ability to differentiate imagining or having an experience of a certain type from any other experiences.

\section{References}

Aleman, A., L. van Lee, M. H. Mantione, I. G. Verkoijen and E. H. de Haan 2001. Visual imagery without visual experience: evidence from congenitally totally blind people. Neuroreport 12: 2601-2604.

Alter, Torin 1998. A Limited Defense of the Knowledge Argument. Philosophical Studies 90: 35-56.

2001. Know-how, Ability, and the Ability Hypothesis. Theoria 67: 229-239.

— 2006. Does Representationalism Undermine the Knowledge Argument? In: Phenomenal Concepts and Phenomenal Knowledge, ed. Torin Alter and Sven Walter. Oxford: Oxford University Press, pp. 65-76.

Bigelow, John and Robert Pargetter 1990. Acquaintance with Qualia. Theoria 56: 129-147.

Clark, Austen 1993. Sensory Qualities. Oxford: Oxford University Press.

— 2000. A Theory of Sentience. Oxford: Oxford University Press.

Conee, Earl 1994. Phenomenal Knowledge. Australasian Journal of Philosophy 72: 136-150.

Gertler, Brie 1999. A Defense of the Knowledge Argument. Philosophical Studies 93: 317-336.

Graham, G. and T. Horgan 2000. Mary, Mary, Quite Contrary. Philosophical Studies 99: 59-87.

2005. Mary Mary, Au Contraire. Philosophical Studies 122: 203212.

Hollins, M. 1985. Styles of mental imagery in blind adults. Neuropsychologia 23: 561-566.

Jackson, Frank 1986. What Mary Didn't Know. Journal of Philosophy 83: 291-295.

— 2006 The Knowledge Argument, Diaphanousness, Representationalism. In: Phenomenal Concepts and Phenomenal Knowledge, ed. Torin Alter and Sven Walter. Oxford: Oxford University Press, pp. $52-64$.

Joyce, Phil 2003. Imagining Experiences Correctly. Proceeding of the Aristotelian Society 103: 361-369. 
Lewis, David 1983. Postcript to 'Mad Pain and Martian Pain.' In: Philosophical Papers, Volume 1. Oxford: Oxford University Press, pp. $130-132$.

1990. What Experience Teaches. In: Mind and Cognition: $A$ Reader, ed. William G. Lycan. Oxford: Blackwell, pp. 499-519.

Loar, Brian 1997. Phenomenal States. In: The Nature of Consciousness, ed. N. Block, O. Flanagan and G. Güzeldere. Cambridge, MA: The MIT Press, pp. 597-616.

Lycan, W. G. 1996. Consciousness and Experience. Cambridge, MA: The MIT Press.

Marotta, J. J. and M. Behrmann 2004. Patient Schn: has Goldstein and Gelb's case withstood the test of time? Neuropsychologia 42: 633-638.

Martin, M. G. F. 2001. Out of the Past: Episodic Recall as Retained Acquaintance. In: Time and Memory: Issues in Philosophy and Psychology, ed. C. Hoerl and T. McCormack. Oxford: Clarendon Press, pp. 257-84.

Matthen, Mohan 2005. Seeing, Doing and Knowing: A Philosophical Theory of Sense Perception. Oxford: Oxford University Press.

McGinn, Colin 2000. Mindsight. Cambridge, MA: Harvard University Press.

Mellor, D. H. 1992/1993. Nothing Like Experience. Proceedings of the Aristotelian Society 93: 1-16.

Nanay, Bence forthcoming. Perception and Imagination: Amodal perception as mental imagery. Philosophical Studies.

Nemirow, L. 1980. Review of Mortal Questions, by Thomas Nagel. Philosophical Review 89: 473-77.

Nemirow, L. 1990. Physicalism and the Cognitive role of Acquaintance. In: Mind and Cognition, ed. W. G. Lycan. Oxford: Blackwell, pp. 490-499.

2006. So This Is What It's Like. In: Phenomenal Concepts and Phenomenal Knowledge, ed. Torin Alter and Sven Walter. Oxford: Oxford University Press, pp. 32-51.

Noordhof, Paul 2003. Something Like Ability. Australasian Journal of Philosophy 81: 21-40.

Raymont, Paul 1999. The Know-How Response to Jackson's Knowledge Argument. Journal of Philosophical Research 24: 113-126.

Raffman, Diana 2005. Even Zombies can be Surprised: A Reply to Graham and Horgan. Philosophical Studies 122: 189-202.

Ryle, Gilbert 1949. The Concept of Mind. London: Huchinson.

Sacks, Oliver 2003. The Mind's Eye. What the blind see. New Yorker July 28, pp. 48-59. 
Stanley, Jason and Timothy Williamson 2001. Knowing How. Journal of Philosophy 98: 411-444.

Tye, Michael 2004. Knowing what it is like: The Ability Hypothesis and the Knowledge Argument. In: There's Something About Mary, ed. Peter Ludlow, Yujin Nagasawa and Daniel Stoljar. Cambridge, MA: The MIT Press, pp. 143-160. 